CERN MT/95-12 (DI)

LHC Note 361

\title{
HOW ENGINEERING DATA MANAGEMENT AND SYSTEM SUPPORT THE MAIN PROCESS FUNCTIONS OF A LARGE-SCALE PROJECT
}

\author{
Ari-Pekka Hameri" , Josephine Schinzel, Reijo Sulonen ${ }^{* *}$
}

\begin{abstract}
By dividing the development process into successive functional operations, this paper studies the benefits of establishing configuration management procedures and of using an engineering data management systems (EDMS) in order to execute the tasks. The underlying environment is that of CERN and the ongoing, a decade long, Large Hadron Collider (LHC)-project. By identifying the main functional groups who will use the EDMS the paper outlines the basic motivations and services provided by such a system to each process function. The implications of strict configuration management on the daily operation of each functional user group are also discussed. The main argument of the paper is that each and every user of the EDMS must act in compliance with the configuration management procedures to guarantee the overall benefits from the system. The pilot EDMS being developed at CERN, which serves as a test-bed to discover the real functional needs of the organisation of an EDMS supports the conclusions. The preliminary experience from the pilot system reveals an urgent need to establish commonly agreed naming and identification system for the LHC-machine. It is also essential to constitute the rules to process engineering and design changes in order to maintain the coherence of the product and to establish feasible grounds on which to proceed with the pilot system to support this process.
\end{abstract}

Keywords: configuration management, engineering data management, large-scale project

Geneva, October 1995

\footnotetext{
"Institute of Particle Physics Technology, Helsinki University of Technology

${ }^{* *}$ Department of Computer Science, Helsinki University of Technology
} 


\section{Introduction}

The fundamental role of an engineering data management system (EDMS) is to support the storage of technical documentation and the multiple processes related to the product's design, manufacturing, assembly, inspection, testing and maintenance, i.e. its whole lifecycle. In a large-scale project with globally distributed design and production processes the task to manage all product related information is of immense importance for the overall project success. This necessitates the use of well defined configuration management processes and a software tool capable of maintaining and controlling all the data and processes related to the development and implementation of the product. These issues are more than timely at CERN* where the design of the Large Hadron Collider (LHC) is well advanced and preliminary plans for its implementation are being devised. By considering earlier accelerators built at CERN the LHC specifications will comprise about 300000 drawings and technical notes, which are produced in almost 40 different countries, as the case is with the experiments. Thus, some kind of an EDMS and related procedures must be established.

Configuration management involves the co-ordination, dissemination and validation of all the information related to product configuration changes. The ultimate goal is to maintain the coherence between the voluminous amount of technical specifications and other data in order to issue and maintain different versions of the product during its development process. In order to manage this task a team is required to mediate confirmed information within the project organisation. An EDMS will provide support for this difficult task. The services provided to a project engineer by the configuration team vary depending on the phase of the project. By dividing the project's life-span in to three main steps, namely conceptualisation, execution (including inspection and testing) and exploitation, the following table (Table 1) summarises broadly the distinctive roles of configuration management and EDMS. The main underlying function of engineering data management is to provide the whole project organisation with a coherent and reliable source of product information.

Rest of the paper is organised in the following way. First, before outlining the main process functions and their needs of product data service, we briefly look at the basic industrial motivations for configuration management. The aim is to highlight how seriously industry is taking the configuration management related investments and what gains have been made from these investments. The project life-span is then divided into process phases to independently define the benefits and services of each step of the project, followed by a review of the preliminary results from the pilot tests with the prototype system being developed at CERN. Finally, conclusions are drawn and future actions concerning the prototype are outlined.

\footnotetext{
* CERN, the European Laboratory for Particle Physics, has its headquarters in Geneva. At present, its Member States are Austria, Belgium, the Czech Republic, Denmark, Finland, France, Germany, Greece, Hungary, Italy, Netherlands, Norway, Poland, Portugal, the Slovak Republic, Spain, Sweden, Switzerland and the United Kingdom. Israel, the Russian Federation, Turkey, Yugoslavia (status suspended after the UN embargo, June 1992), the European Commission and Unesco have observer status.
}

Hameri, A.-P., Schinzel, J., Sulonen, R. "How Engineering Data Management and System Support the Main Process Functions of a Large-Scale Project", Helsinki University of Technology \& CERN, October, 1995. 


\begin{tabular}{|c|c|c|c|}
\hline \multicolumn{4}{|c|}{ The supportive actions of configuration management and EDMS } \\
\hline & Conceptualisation & Execution & Exploitation \\
\hline $\begin{array}{l}\text { Configuration } \\
\text { management }\end{array}$ & $\begin{array}{ll}\text { - } & \text { translates customer } \\
\text { requirements into } \\
\text { technical language } \\
\text { - } \text { manages version handling } \\
\text { - } \text { maintains product } \\
\text { coherence } \\
\text { - } \begin{array}{l}\text { controls specification and } \\
\text { design changes }\end{array}\end{array}$ & $\begin{array}{l}\text { - } \text { ensures product's } \\
\text { manufacturability } \\
\text { disseminates } \\
\text { technical information } \\
\text { between vendors and } \\
\text { project teams } \\
\text { controls specification } \\
\text { and design changes }\end{array}$ & $\begin{array}{l}\text { - supports operational } \\
\text { and maintenance } \\
\text { activities of the system } \\
\text { - provides a base of } \\
\text { learning for future } \\
\text { - } \\
\text { summarises } \\
\text { specification and } \\
\text { design changes }\end{array}$ \\
\hline $\begin{array}{l}\text { Engineering data } \\
\text { management } \\
\text { system }\end{array}$ & $\begin{array}{l}\text { - } \\
\text { - } \text { provides user interface to } \\
\text { all product data } \\
\text { - } \text { maintains design process } \\
\text { status } \\
\text { - } \\
\text { supports dissemination of } \\
\text { technical information }\end{array}$ & $\begin{array}{l}\text { provides continuous } \\
\text { source of up-to-date } \\
\text { product information } \\
\text { supports technical } \\
\text { communication } \\
\text { between project } \\
\text { collaborators from } \\
\text { bids to project closure }\end{array}$ & $\begin{array}{l}\text { provides data for an } \\
\text { aftermath and learning } \\
\text { from the design } \\
\text { process } \\
\text { helps tracing solutions } \\
\text { to maintenance and } \\
\text { operational problems }\end{array}$ \\
\hline $\begin{array}{l}\text { Main } \\
\text { contribution of } \\
\text { EDMS }\end{array}$ & $\begin{aligned} & \Rightarrow \text { support and co-ordination } \\
& \text { of engineering work/ } \\
& \text { information/data flow } \\
& \Rightarrow \text { quality of design }\end{aligned}$ & $\begin{aligned} \Rightarrow & \text { mediation between } \\
& \text { customer, production } \\
& \text { and design } \\
\Rightarrow & \text { quality of } \\
& \text { manufacturing }\end{aligned}$ & $\begin{aligned} \Rightarrow & \text { maintain operational } \\
& \text { period and establishes } \\
& \text { learning process } \\
\Rightarrow & \text { lifetime support }\end{aligned}$ \\
\hline
\end{tabular}

Table 1. The value-adding functions and services of configuration management and EDMS.

\section{Motivation from industrial point of view}

Industrial companies have realised the huge potential hidden in the control of design and engineering changes. The annual markets around EDMSs are estimated to boom from 1994's \$400 million with an average 30\% annual growth to almost \$1.2 billon in 1998 (CIMdata, 1994). It has been predicted that documentation management will be among the fastest growing software niches after the network applications by the end of this century. The reasons for this are obvious. Manufacturing enterprises have mostly focused their development efforts on operations management according to main prevailing manufacturing hypes, such as business process reengineering and lean manufacturing. The next potential area of development emerges from efficient information management. The ultimate goals of both of these drives remain the same: reduce time to market, shorten design review cycle, reduce manufacturing lead times, increase in productivity, reduce rework, etc. Another necessary prerequisite is the fact that all documents will eventually be produced and handled in electronic form.

Although it is difficult to get exact quantitative data on the net benefits and the investments on EDMS and configuration management, some facts, figures, results and management actions may be found publicly available:

- Several U.S. based companies have started to establish electronic archives for their technical documentation by scanning thousands of technical data items into a database (Puttre, 1992).

Hameri, A.-P., Schinzel, J., Sulonen, R. "How Engineering Data Management and System Support the Main Process Functions of a Large-Scale Project", Helsinki University of Technology \& CERN, October, 1995. 
- A company producing large industrial production units indicated that on the average half of their design and engineering effort is related to searching for technical documentation (Nihtilä, 1995).

- One industrial facility producer estimated that they have 4 million technical drawings and when new order comes in they have $80 \%$ probability of having the needed drawings ready, yet the odds to find them is $4 \%$ (Sulonen, 1995).

- Global electronic company reduced change order cycle from 33 days to less than 10 , halved the time needed to devise technical manuals and eliminated micro-fiche through the introduction of a product data management system with an objective of paperless documentation management (Frederick. 1995).

- Multinational computer and electronic company reduced its staff required to manage documentation load with $35 \%$, plummeted storage cost/year/document from $50 \$$ to $5 \$$ and improved significantly the document handling efficiency during a 5 year EDM project during which own EDMS was developed (McCrea and D'Agostino, 1995).

- A leading microprocessor manufacturer developed with the effort of 7 engineering years global, standard and PC based EDM procedures with vendor access; results mount in efficient document handling, paperless document process and up-to-date information (Hargrave, 1995).

The above examples illustrate well the potential hidden in efficient configuration management and in central storing of all information. Predominantly the results have been attained through the introduction of new managerial principles supported by an EDMS to maintain, control and archive all the design and specification changes. Sherpa Corporation (CIMdata, 1994) lists (Table 2.) the following results gained by its customers before and after implementing Sherpa's PDM system.

\begin{tabular}{|l|c|c|c|}
\hline \multicolumn{1}{|c|}{ Category } & Pre-PDM & Post-PDM & \% Reduction \\
\hline Engineering change cycle & 61.5 days & 10.25 days & $83 \%$ \\
\hline Cost per change & $\$ 4,200$ & $\$ 1,500$ & $64 \%$ \\
\hline Processing engineering change orders & $60 /$ month & $<5 /$ month & $92 \%$ \\
\hline Product development cycles & 33 months & 24 months & $27 \%$ \\
\hline Build-to-order cycles & 9 weeks & 3 weeks & $67 \%$ \\
\hline Average \# of part lists & 8 & 2 & $75 \%$ \\
\hline
\end{tabular}

Table 2. Average time and cost savings resulting from Sherpa's PDM system use (Data Supplied by Sherpa Corporation).

Multiple sources report that investments on EDM and supporting systems have pay-back times from one to three years. In addition the positive trend from the investment tends to continue even after three years when the full benefits of the system start rolling in. From CERN's point of view the needs and motivations for configuration mangement and the relating EDMSs originate from the particular structure of the organization:

- the LHC-project is by definition a global project with actors from all over the world;

- CERN is facing pressures to cut down its operational expenditures and at the same time build a new accelerator;

- by the end of the century CERN will reduce its staff members from the present 3000 to approximately 2000;

Hameri, A.-P., Schinzel, J., Sulonen, R. "How Engineering Data Management and System Support the Main Process Functions of a Large-Scale Project", Helsinki University of Technology \& CERN, October, 1995. 
- despite the large-scale of the LHC-project other, on-going projects, must be finished successfully and therefore resources available must be shared between multiple projects;

- today $20 \%$ of CERN's overall working effort is related to LHC, this portion will increase in the coming five years up to $80 \%$;

- CERN is obliged to increase industrial out-sourcing and service contracting.

These requirements ask for a flexible project organization with a capability to evolve and maintain level of expertise level through the conceptualization, design, manufacturing, assembly, installation and operational phases of the project. To manage this the existing expertise of the organization must be carefully mapped and allocated along with existing projects to correspond to the LHC's technological requirements and other project objectives. In addition the expertise and the related technical documentation must be controlled and stored to maintain the configuration coherence and their availability as the organization diminishes its resources. As well as from the expertise and configuration related aspects of the organization, communication plays a major role. Below we concentrate on the benefits of configuration management to the organisation and leave the other aspects for the subjects of later research.

\section{Process functions - the user point of view}

CERNs unique environment makes it difficult to pin-point the potential users of EDM services. Individuals tend to execute many roles during the progress of the project; e.g. an engineer may be responsible for designing, manufacturing and even installing a certain component and, thus, the services needed depend on which phase the work is progressing. To avoid misunderstandings by classifying the users according to their official function we proceed by describing the user point of view in terms of the processes or functions needed to finish the project. In the introduction the whole project was divided into three main phases, namely conceptualisation, execution and exploitation. These phases are decomposed further. Figure 1 summarises the further division of the project into consecutive processes.

\begin{tabular}{|c|c|c|}
\hline \multicolumn{3}{|c|}{$\begin{array}{l}\text { Project management/administration/finance } \\
\Rightarrow \text { planning, scheduling \& control } \\
\Rightarrow \text { risk management } \\
\Rightarrow \text { supplier integration }\end{array}$} \\
\hline \multicolumn{3}{|c|}{ multiple interaction and feed-back } \\
\hline $\begin{array}{l}\text { Conceptualisation } \\
\Rightarrow \text { abstraction } \\
\Rightarrow \text { conceptualisation } \\
\Rightarrow \text { technical design \& engineering } \\
\Rightarrow \text { technical documentation }\end{array}$ & $\begin{array}{c}\text { Execution } \\
\Rightarrow \text { manufacturing } \\
\Rightarrow \text { quality management } \\
\Rightarrow \text { assembly } \\
\Rightarrow \text { installation }\end{array}$ & $\begin{array}{c}\quad \text { Exploitation } \\
\Rightarrow \text { operation } \\
\Rightarrow \text { maintenance } \\
\Rightarrow \text { learning } \\
\Rightarrow \text { system demolition }\end{array}$ \\
\hline
\end{tabular}

time $\longrightarrow$

Figure 1. The main functional processes of each task to accomplish the LHC-system.

Hameri, A.-P., Schinzel, J., Sulonen, R. "How Engineering Data Management and System Support the Main Process Functions of a Large-Scale Project", Helsinki University of Technology \& CERN, October, 1995. 
It should be emphasised that the status of the whole LHC-project at a certain time is the sum of the phases of the many sub-projects comprising the whole project. Each individual equipment or part of the LHC-system undergoes predefinable phases and if it belongs to a sub-system follows the schedule of this system.

The main services and benefits of an EDM and the related systems (together to be referred as EDM procedures) are outlined below from the point of view of each process of the LHCproject. The perspective is that of the LHC-project, which can be compared to other largescale projects with significant technological challenges, which require more than decade's duration and global collaboration.

\section{Project management/administration/finance}

- Planning, scheduling and control of the project resources and work flow is the fundamental activity of project management. Decisions concerning resource allocation may be supported by following the amount of engineering changes and how they have evolved in each major task of the project work structure. Once the project is progressing the main task of project management is to keep the project in schedule and to solve problems as they emerge. Detailed reporting of the design changes and other problems retarding the work flow are mediated almost on-line to the project management via efficient EDM procedures.

- Risk management and anticipation of possible near future technological pitfalls is a difficult, yet important, task of the project management. The preventive problem solving activities benefit greatly from the up-to-date information on how technical development is progressing and what problems have been spotted. In global projects this information carries also the possibility to follow how communication has evolved around certain technical documents and who has been needing them. This feature of electronic communication around EDM procedures provides the management with an extension to normal progress reporting to know how the work has actually been progressing. Tracking of the communication behaviour gives the management an extra facet to tackle and anticipate technological risks.

- Supplier integration and logistics is a mandatory activity for any large-scale project. Operational LHC-system is the ultimate sum of multiple contributions from huge variety public, academic and industrial partners, most of them needing a flexible and reliable access to the diverse technical documents defining the system. This requirement of integrating the suppliers with the EDM procedures, is vital to get full commitment of the suppliers. In addition it establishes the means to control suppliers and to communicate with them on technical level. Also issues concerning data security are of great importance when external communication is concerned.

\section{Conceptualisation}

- Abstraction is a process, typical to large-scale scientific projects, during which the ultimate system, such as the LHC, is disassociated from the overall realm of thoughts around the subject matter. With LHC this process results in the lattice model of the system with its capabilities, objectives and features termed in the language of physicists. The lattice model already shares the main technological features of the system and acts as the initial model for the planning of the overall system. As the project proceeds the lattice serves merely as a view among the others of the system. The EDM procedures should take the lattice model as the first model of the system and later on, as the work proceeds, link it with other views of the system. Here the different views of the system refer to the

Hameri, A.-P., Schinzel, J., Sulonen, R. "How Engineering Data Management and System Support the Main Process Functions of a Large-Scale Project", Helsinki University of Technology \& CERN, October, 1995. 
fact that the EDMS must be flexible enough to provide a working environment customised to serve the peculiar needs of the various processes and technologies involved with the project.

- Conceptualisation processes and concretises the lattice model or the system abstraction into a conception of the detailed technical needs with key parameters and their values. At CERN the conceptual model at a moment in time can be seen to be the so called 'White Book' describing the technical details of the LHC-system. Yet, the White Book is obsolete already when printed and the EDMS would provide a dynamic White Book. The conceptual model establishes the fundamental structure for the technical document handling. This underlying structure acts as the skeleton of the product breakdown structure. EDM procedures are used to maintain the conceptual model in coherence with original lattice model. At its best the EDMS serves as a communication medium during the process of establishing the model. Ultimately the EDMS will provide all project collaborators with an easy access to the up-to-date conceptual model of the system.

- Technical design and engineering processes are the prime beneficiaries of the EDM procedures. Design materialises the conceptual model into technical details with their planned interaction with each other to meet the original functional requirements. Engineering activities further adjust the design into exact technical specifications with material, manufacturing and assembly instructions. This activity produces also various technical notes and test reports, which are vital to the coming activities. EDM procedures provide the designers and engineers with an intuitive and easy access to the actual technical information i.e. documents and controls their coherence with each other and compliance with the original plans. The management procedures controlling the design and specification changes benefit from the EDMS as media to archive, distribute and control the design status of the system.

- Technical documentation process during the whole conceptualisation phase generates a huge amount of technical notes, test reports, drawings, CAD models, instructions, etc. The fundamental reason for the emergence of EDMSs in industry has been in the coordination of this voluminous amount of data. Whatever the database or hardware solution the EDMS provides the project organisation with a logically centralised interface to the information with adequate retrieval mechanisms.

\section{Execution}

- Manufacturing is often a parallel process with the design and engineering processes. This is due to the need for pilot and prototype testing, which are used intensively in projects like the LHC to test the feasibility of the technological solution. During manufacturing the design is first time tested in reality and the coefficient in error correction is a decade higher than during the design and engineering. EDMS procedures ensure the manufacturability of each part specification by taking into account the constraints of the production facilities. In addition the EDMS serves as a flexible medium to retrieve the latest information related to part manufacturing, assembly, quality and material instructions.

- Quality management is here referred as part of the execution phase, although in general the EDM procedures focus on better design and engineering quality through all process phases. The EDM procedures support quality management with continuous access to the multiple change log generated by the diverse processes of the project. The alternating methods of quality management may utilise this information to complement their normal sources of information. This enables the quality management, not only to remove

Hameri, A.-P., Schinzel, J., Sulonen, R. "How Engineering Data Management and System Support the Main Process Functions of a Large-Scale Project", Helsinki University of Technology \& CERN, October, 1995. 
problems related to operational activities, but also to improve the whole process within which the actions take place.

- Assembly, i.e. the process of fitting together manufactured parts into a complete unit of a machine, needs to incorporate numerous part and assembly information details to perform its task. An EDMS supports this by collecting the needed information according to the hierarchical product breakdown structure. Configuration management assures the compatibility of this information.

- Installation process is the final set-up of the system after which the operational phase of the system may commence. To achieve this multiple information is needed concerning the sub-assemblies and the final assembly site. By taking into account the site and other installation related constraints, the final assembly or installation breakdown structure forms another view of the system being built. An EDMS maintains this information in such a form that the configuration management maintains the product coherence with the installation information.

\section{Exploitation}

- Operation, i.e. the practical work with the installed system, benefits from the centralised source of technical information when interpreting the results produced by the system. Well established technical documentation speeds up the system start-up and provides the operators with an information source for profound understanding of the system.

- Maintenance of the system requires well documented system history to succeed in its task. In a project with long duration and involvement of multiple resources the detailed documentation of the system's change history prepares ground for smooth and efficient maintenance operations. The EDM procedures produce a full evolutionary perspective to the system design and reveals how the system was technologically completed, which helps greatly the maintenance and problem reparation work. Also machine development and physics analysis requires access to past, current and future view of the accelerator.

- Learning, not only after but during the project is important and apparent feature of successful long-term projects. EDM procedures produce structured information which enables to induce exogenous learning inside the project organisation. Reported instructions on changes and tackled problems increase the knowledge and skills of the organisation, which eventually helps to avoid the making of the same mistakes.

- System demolition, a major project of itself, will inevitably take place in one day or another. To manage the task in environment, time and cost efficient way the documented technical details of the system are needed. Thus, the EDM procedures serve the whole life-cycle of the system.

\section{Experiences with the prototype}

A prototype has been and is being developed at CERN to pre-screen organisation's basic needs from an EDMS. The pilot system is based on the commonly applied database solution at CERN and is accessible via existing communication network. The prototype is referred as ACCelerator Information System (ACCIS). At its current stage ACCIS enables to:

- operate on all CERN supported client platforms;

- store hierarchical structures with references to the respective documentation;

- maintain multiple views of the stored product data structures;

- commission different versions of the product structure;

Hameri, A.-P., Schinzel, J., Sulonen, R. "How Engineering Data Management and System Support the Main Process Functions of a Large-Scale Project", Helsinki University of Technology \& CERN, October, 1995. 
- interactively navigate through product structure;

- access other exiting data than the one in the database.

Thus, in short ACCIS is an ORACLE based generic configuration management system capable of dynamic documentation of any complex system or organization. These features of ACCIS have been tested in three pilot projects focusing on three completely different views or subsystems of the accelerator. One concerns the short straight sections (SSS) of the machine, another focuses on the lattice model of the whole LHC-system and last one consists of an implementation of the product breakdown structure with assembly information of the proton-synchrotron booster. The first one to be viewed is the SSS, which high-lights the analysis work needed to establish relevant classes and structures of the subsystem.

The SSS-case. The work was originally aimed to test the userinterface and usability in general of the prototype system. Along with many minor revisions to the system the work resulted a product breakdown structure of the SSS, with preliminary description of the parts needed and how they are linked together. As the work was carried out by a skilled computer specialist ignorant of the product itself, a significant effort was made to translate the existing, spreadsheet and self-purpose based product structure of the product in to the ACCIS. This required classification and analysis work, yet after the work was done the system has provided an intuitively and easily understandable view of the product structure. This has been used to further develop and exploit the system. The lesson learned was that system initialization and the very first steps of structuring product related data requires careful planning and the participation of the engineers' themselves. In addition it was realized that using any kind of formalized representation of the product structure flexibility is needed from the system to fulfill the multiple needs to view the same product structure. In parallel an assembly model of LHC with the SSS main components positioned in the tunnel was entered and the assmbly componets linked to the specification details.

If the previous example revealed something of the initial work to be performed before fully exploiting the system, the following example shows the diverse possibilities to use the ACCIS.

The lattice case. An important component of the LHC project is the theoretical model of the machine (the lattice) which is used to study the charged-particle optics of the accelerator using the MAD (Methodical Accelerator Design) program. In order to study the feasibility of managing a highly structured lattice model, the data, contained in a flat file, was loaded into ACCIS where it can be consulted, copied or modified. Software has also been developed to extract the model in a format which can be read by MAD. Future developments might include using ACCIS as the source of data for direct input into MAD and for storing data calculated by the MAD-program. For future work it is proposed to study the conversion from MAD results through geometric model to a $\mathrm{CAD}$ picture of the accelerator.

The following example emphasises the anticipations from the ACCIS system, once the possibilities of its capability were realized.

The Booster-case. The PS BOOSTER-team plans to use ACCIS for daily operation and in particular to provide input for the Beam Optics package which is used for e.g. the Automatic Beam Steering control programs. The layout of the machine has been implemented as a hierarchical structure in the ACCIS. Documentation of the BOOSTER has so far mainly been based on up-to-date notes on elements and operational aspects of the machine. This documentation is being collected in ACCIS, which will provide in flexible manner the user with the geometric measures, field measures, information on personnel, history of settings, location of elements and associated equipment and simple drawings of the machine. In the near future links will be implemented to other CERN databases such as the general CERN directory, the PS control database and the AutoCad drawings database.

Hameri, A.-P., Schinzel, J., Sulonen, R. "How Engineering Data Management and System Support the Main Process Functions of a Large-Scale Project", Helsinki University of Technology \& CERN, October, 1995. 
All of these cases are still valid and the work is progressing by refining the ACCIS in small steps to better comply with the needs. To summarise, to date, the experiences from the prototype EDMS have been very illuminating from three different point of views:

- Preliminary work; the work has given an idea of the work load needed before full exploitation of the system is possible. The cases show that product related information is highly scattered around the organisation and that even similar information is represented in alternating formats. To collect this information in a logically centralised database is vital for the future functionality of CERN as the expertise tend to leave the organisation gradually.

- Multiple benefits; coherent maintenance of the product breakdown structure with all the relevant engineering information serves also other purposes than those related to engineering information/work/data control. The case users haverealised that the system may act as a source of input information to other systems or as a place to store outputs from other systems. The unexpected usage of the pilot system show well how beneficial it is to have logically centralised source of product information.

- CERN's requirements; by dealing with real world products and data the true needs and gains from an EDMS have been initially identified during the prototype tests. First of all the multitude and diversity of the information related to accelerator subsystems is striking, yet not unmanageable. On the other hand the different functions in the beginning of the project life-cycle share strongly divergent needs. This fact insists on finding the "vein" of information that interests everybody which should form the skeleton of the EDMS and to which each function establishes its own view along their own special information.

\section{Conclusions and future actions}

By taking into account the whole life-cycle of the LHC-system the paper has outlined the main benefits and services from the EDM procedures. From CERN's point of view the configuration management and the supporting tools are very important both for the LHC experiments and machine. Manufacturing industry is already showing the way with strong involvement on implementing alternative EDM procedures. CERN is at cross-roads as the technological complexity of the system meets with diminishing resources; the design history and the knowledge must be stored somewhere to establish secured operational period for the system along with initiation of learning processes from the past experience.

Systematic configuration management at CERN is still at its infancy. Teams and subprojects do take care of their own work flow by following traditional routines, yet the overall management of the product integrity lacks management procedures. Fortunately, it has been widely recognised that there exists an urgent need to establish procedures to control engineering changes. Following actions need to be taken urgently:

1. To establish a configuration management team with responsible representatives from all major subsystems of the LHC machine. The experiments should form similar teams and they should meet frequently the machine people.

Hameri, A.-P., Schinzel, J., Sulonen, R. "How Engineering Data Management and System Support the Main Process Functions of a Large-Scale Project”, Helsinki University of Technology \& CERN, October, 1995. 
2. The teams define similar protocols, review cycles and communication media to control, inform and disseminate design changes in product specifications between each other and other collaborators of the project.

3. Launch activities to define, identify, gather and manage all configuration related information into a logically centralized repository.

4. Document every change, with a reference to the original problem, responsible people and implications to the configuration.

5. The teams must construct united view of the requirements set to an EDMS that represent the overall needs of CERN.

6. Define a strategy for putting in place an EDMS.

On the EDMS the work at CERN has been progressing in parallel trajectories. The accelerator or machine people have been studying the needs of such a system with rather moderate effort and the experimental staff have been searching the available tools from the markets. It is vital that these two streams of activities are merged into one to establish a complete CERN view on the needs and requirements of such a system. The pilot work supports this activity enormously as it deals with real world situations at CERN. Concerning the prototype the following near future development efforts will be completed:

- implement the LHC parameter classes with their current values;

- references to documents will be extended to the actual control of the documents;

- assure the launching of different documents in the server environment;

- study and establish WWW interface to the prototype;

- fully implement the version handling;

- test the engineering change process control features.

When these functionalities have been implemented to the ACCIS prototype the basic characteristics of an EDMS system are available for the organisation. This work is increasingly associated with empirical work around the LHC-system's technical documentation. Progress and results will be disseminated frequently and demonstrationsheld to people responsible for configuration management.

\section{Acknowledgements}

The authors are thankful for the support from the users of the prototypes, especially for Eeva-Leena Onnela and Mats Lindroos.

\section{References}

[1] CIMdata Inc., PDM Buyers Guide, CIMdata Incorporation, U.S., 1994.

[2] Frederick, M., "Case Study: Achieving Buy-In", 12th International Conference on Enterprise PDM: The Next Generation, Boston, Massachusetts, May 15-16, 1995.

[3] Hargrave, R., "Building a PDM System for Immediate Value and Long Range Potential', 12th International Conference on Enterprise PDM: The Next Generation, Boston, Massachusetts, May 15-16, 1995.

Hameri, A.-P., Schinzel, J., Sulonen, R. "How Engineering Data Management and System Support the Main Process Functions of a Large-Scale Project", Helsinki University of Technology \& CERN, October, 1995. 
[4] McCrea, S., D'Agostino, P., After the Pilot", 12th International Conference on Enterprise PDM: The Next Generation, Boston, Massachusetts, May 15-16, 1995.

[5] Nihtilä, J., Integration mechanisms in new product development, Helsinki University of Technology, Manuscript of a Dissertation, Espoo, 1995.

[6] Puttre, M., "Document Management: Establishing an Electronic Archive", Mechanical Engineering, pp. 74-78, January, 1992.

[7] Sulonen, R., "Product Data Management", Hewlett-Packard seminar, Espoo, Finland, 1.6.1995.

Hameri, A.-P., Schinzel, J., Sulonen, R. "How Engineering Data Management and System Support the Main Process Functions of a Large-Scale Project", Helsinki University of Technology \& CERN, October, 1995. 